\title{
Efficacy and safety of nintedanib in patients with advanced idiopathic pulmonary fibrosis
}

Luca Richeldi $i^{*}$ D, Martin Kolb², Stéphane Jouneau ${ }^{3}$, Wim A. Wuyts ${ }^{4}$, Birgit Schinzel $^{5}$, Susanne Stowasser ${ }^{5}$, Manuel Quaresma ${ }^{5}$ and Ganesh Raghu ${ }^{6}$

\begin{abstract}
Background: The two 52-week INPULSIS trials investigated nintedanib versus placebo in patients with IPF, FVC $\geq 50 \%$ predicted and DLCo 30-79\% predicted. The 24-week INSTAGE trial investigated nintedanib plus sildenafil versus nintedanib alone in patients with IPF and DLco $\leq 35 \%$ predicted. We used data from INPULSIS and INSTAGE to compare the effects of nintedanib in patients with IPF with less versus more severe impairment in gas exchange at baseline.
\end{abstract}

Methods: Analyses were conducted in patients treated with nintedanib alone in the INPULSIS and INSTAGE trials and in patients treated with placebo in the INPULSIS trials. Outcomes included the rate of decline in FVC over 24 weeks, the proportions of patients who had a confirmed or suspected idiopathic acute exacerbation over 24 weeks, deaths over 24 weeks, and adverse events. Analyses were descriptive.

Results: In total, 638 and 136 patients received nintedanib alone in the INPULSIS and INSTAGE trials, respectively, and 423 patients received placebo in the INPULSIS trials. Rates of FVC decline were -52.3 and $-66.7 \mathrm{~mL} / 24$ weeks in patients treated with nintedanib alone in INPULSIS and INSTAGE, respectively, and $-102.8 \mathrm{~mL} / 24$ weeks in patients treated with placebo in INPULSIS. Confirmed or suspected idiopathic acute exacerbations were reported in 0.6 and $3.7 \%$ of patients treated with nintedanib alone in INPULSIS and INSTAGE, respectively, and $2.1 \%$ of patients treated with placebo in INPULSIS. Deaths occurred in 2.0, 11.0 and 1.9\% of patients in these groups, respectively. Diarrhoea adverse events were reported in 52.5 and $48.5 \%$ of patients treated with nintedanib alone in INPULSIS and INSTAGE, respectively, and $16.1 \%$ of patients treated with placebo in INPULSIS.

Conclusions: Based on data from the INSTAGE and INPULSIS trials, nintedanib had a similar effect on FVC decline over 24 weeks, and a similar safety and tolerability profile, in patients with IPF and more versus less severe impairment in gas exchange. These data support the use of nintedanib in patients with IPF who have advanced disease.

Trial registration: INPULSIS (NCT01335464 and NCT01335477); INSTAGE (NCT02802345).

Keywords: Clinical trial, Interstitial lung diseases, Tyrosine kinase inhibitor, Vital capacity

\footnotetext{
* Correspondence: luca.richeldi@policlinicogemelli.it

${ }^{1}$ Fondazione Policlinico A. Gemelli IRCCS, Università Cattolica del Sacro

Cuore, Rome, Italy

Full list of author information is available at the end of the article
}

(c) The Author(s). 2020 Open Access This article is distributed under the terms of the Creative Commons Attribution 4.0 International License (http://creativecommons.org/licenses/by/4.0/), which permits unrestricted use, distribution, and reproduction in any medium, provided you give appropriate credit to the original author(s) and the source, provide a link to the Creative Commons license, and indicate if changes were made. The Creative Commons Public Domain Dedication waiver (http://creativecommons.org/publicdomain/zero/1.0/) applies to the data made available in this article, unless otherwise stated. 


\section{Background}

Idiopathic pulmonary fibrosis (IPF) is a progressive fibrosing interstitial lung disease associated with decline in lung function, worsening dyspnoea and quality of life, and considerable mortality $[1,2]$. While IPF progresses in all patients, the pattern of disease progression is variable and remains a challenge to predict [3, 4]. A better evidence base for the treatment of severe IPF remains an unmet need [5].

Nintedanib is a treatment for IPF. In the two 52-week INPULSIS trials, nintedanib reduced the annual rate of decline in forced vital capacity (FVC) (mL/year) by approximately $50 \%$ compared with placebo in patients with IPF and mild or moderate impairment in lung function at baseline, with an adverse event profile predominantly characterised by gastrointestinal events [6]. In the 24week INSTAGE trial, nintedanib plus sildenafil was associated with a numerical but not statistically significant benefit on change in St. George's Respiratory Questionnaire (SGRQ) total score compared with nintedanib alone in patients with IPF and severely impaired gas exchange (diffusing capacity of the lungs for carbon monoxide [DLco] $\leq 35 \%$ predicted) at baseline [7].

Few data are available on the efficacy and safety of antifibrotic therapies in patients with advanced IPF. We used data from the INPULSIS and INSTAGE trials to compare the effects of nintedanib in patients with IPF and less versus more severe impairment in gas exchange at baseline.

\section{Methods}

The designs of the INPULSIS and INSTAGE trials have been published $[6,7]$. Briefly, in the INPULSIS trials, patients with FVC $\geq 50 \%$ predicted and DLco $30-79 \%$ predicted were randomised $3: 2$ to receive nintedanib $150 \mathrm{mg}$ twice daily (bid) or placebo for 52 weeks, with a follow-up visit 4 weeks later. The primary endpoint was the annual rate of decline in FVC (mL/year) [6]. In the INSTAGE trial, patients with IPF and DLco $\leq 35 \%$ predicted were randomised $1: 1$ to receive nintedanib 150 mg bid plus sildenafil or nintedanib $150 \mathrm{mg}$ bid plus placebo for 24 weeks, with a follow-up visit 4 weeks later. The primary endpoint was the change from baseline in SGRQ total score at week 12 [7]. In all these trials, FVC data were converted to per cent predicted values using the European Community for Steel and Coal equations [8]. In the INPULSIS trials, DLco data were converted to $\%$ predicted using the equation published by Crapo [9]. In INSTAGE, sites used different equations to calculate per cent predicted values for DLco.

Spirometry was performed at baseline and weeks 2, 4, 6, 12 and 24 in the INPULSIS trials [6], and at baseline and weeks 4, 8, 12, 18 and 24 in the INSTAGE trial [7]. The SGRQ was completed by patients at baseline and weeks 6, 12 and 24 in the INPULSIS trials [6], and at baseline and weeks 4, 12 and 24 in the INSTAGE trial [7]. The SGRQ assesses health-related quality of life (HRQL); there are 50 items and the total score ranges from 0 to 100 , with higher scores indicating worse HRQL [10]. In the INPULSIS trials, acute exacerbations were defined as events that met the following criteria: unexplained worsening or development of dyspnoea within 30 days; new diffuse pulmonary infiltrates on chest X-ray and/or HRCT parenchymal abnormalities with no pneumothorax or pleural effusion (new groundglass opacities) since last visit; causes of the acute worsening, including infection, left heart failure, pulmonary embolism, or any identifiable cause of acute lung injury excluded as per routine clinical practice and microbiological studies [6]. In the INSTAGE trial, an acute exacerbation was defined as an event that met the following criteria: acute worsening or development of dyspnoea, typically of less than 1-month duration; computed tomography with new bilateral ground-glass opacity and/or consolidation superimposed on background pattern consistent with usual interstitial pneumonia pattern; deterioration not fully explained by cardiac failure or fluid overload; extra-parenchymal causes (e.g. pneumothorax, pleural effusion, pulmonary embolism) were excluded [7]. In both the INPULSIS and INSTAGE trials, acute exacerbations were adjudicated by a blinded committee as confirmed, suspected, or not acute exacerbations [6.7]. In the INPULSIS trials, events deemed to be acute exacerbations but did not meet all protocolspecified criteria for an acute exacerbation were classified as suspected acute exacerbations [6]. In the INSTAGE trial, events deemed to be acute exacerbations but had missing CT data were classified as suspected acute exacerbations [7]. In the INSTAGE trial, confirmed/suspected acute exacerbations were further adjudicated as idiopathic or triggered based on the criteria described in the 2016 international working group report $[7,11]$. All confirmed/ suspected acute exacerbations in the INPULSIS trials were idiopathic [6].

In the current analyses, we investigated changes from baseline in FVC (mL) and SGRQ total score at weeks 12 and 24; the rate of decline in FVC (mL) over 24 weeks; and the proportions of patients who had an absolute decline in FVC $\geq 5 \%$ predicted or died, had an adjudicated confirmed or suspected idiopathic acute exacerbation, or who died from any cause over 24 weeks in patients who received nintedanib alone in the INPULSIS and INSTAGE trials and in patients who received placebo in the INPULSIS trials. For each endpoint, the same statistical approach was used as in the primary analyses [6, 7]. Changes from baseline in FVC and SGRQ total score at weeks 12 and 24 were analysed using mixed effects models for repeated measures. The rate of 
decline in FVC over 24 weeks was analysed using a random coefficient regression model. These models allowed for missing data, assuming they were missing at random.

Adverse events were reported by the investigators irrespective of causality and coded based on preferred terms in the Medical Dictionary for Regulatory Activities (MedDRA) (version 20.1 in INPULSIS and version 21.0 in INSTAGE) [6, 7]. In the INPULSIS trials, adverse events with onset between the first dose of trial drug and day 195 (or between the first dose and 28 days after the last dose for patients who discontinued trial drug before week 24) were included [6]. In the INSTAGE trial, adverse events with onset between the first dose and up to 28 days after the last dose of trial drug were included. Safety analyses were descriptive [7]. All efficacy and safety analyses were based on patients who received $\geq 1$ dose of trial drug.

\section{Results}

\section{Patients}

Overall, 638 and 136 patients received nintedanib alone in the INPULSIS and INSTAGE trials, respectively; 423 patients received placebo in the INPULSIS trials. In accordance with the eligibility criteria, mean DLco \% predicted at baseline was higher in INPULSIS than in INSTAGE (47.2\% versus $25.6 \%$ predicted). In addition, patients in the INPULSIS trials were younger and had higher FVC \% predicted and lower SGRQ total score (indicating better health-related quality of life) than patients in the INSTAGE trial (Table 1).

\section{Lung function}

Mean (SE) absolute changes from baseline in FVC at week 12 were - 25.4 (9.8) and - $25.5(15.7) \mathrm{mL}$ in patients treated with nintedanib alone in INPULSIS and INSTAGE, respectively, and $-78.8(11.3) \mathrm{mL}$ in patients treated with placebo in INPULSIS (Fig. 1). Mean (SE) absolute changes from baseline in FVC at week 24 were - 52.8 (9.8) and 58.2 (19.6) $\mathrm{mL}$ in patients treated with nintedanib alone in INPULSIS and INSTAGE, respectively, and - 106.4 (11.4) $\mathrm{mL}$ in patients treated with placebo in INPULSIS (Fig. 2). The rate of decline in FVC (mL) over 24 weeks was consistent with the changes from baseline in FVC (mL) at week 24 (Fig. 3).

Over 24 weeks, an absolute decline in FVC $\geq 5 \%$ predicted or death occurred in 190 (29.8\%) and 69 (50.7\%) patients treated with nintedanib alone in INPULSIS and INSTAGE, respectively, and 174 (41.1\%) patients treated with placebo in INPULSIS.

\section{Health-related quality of life}

Mean (SE) changes from baseline in SGRQ total score at week 12 were $0.38(0.51)$ and $-0.77(1.0)$ in patients treated with nintedanib alone in INPULSIS and INSTAGE, respectively, and $0.10(0.61)$ in patients treated with placebo in INPULSIS. Mean (SE) changes in SGRQ total score at week 24 were $1.05(0.53)$ and 2.42 (1.16) in patients treated with nintedanib alone in INPULSIS and INSTAGE, respectively, and $1.78(0.68)$ in patients treated with placebo in INPULSIS.

\section{Acute exacerbations and mortality}

Confirmed or suspected idiopathic acute exacerbations occurred in $4(0.6 \%)$ and $5(3.7 \%)$ patients treated with nintedanib alone in INPULSIS and INSTAGE, respectively, and $9(2.1 \%)$ patients treated with placebo in INPULSIS. Deaths occurred in 13 (2.0\%) and 15 (11.0\%) patients treated with nintedanib alone in INPULSIS and

Table 1 Baseline characteristics of patients in the INPULSIS and INSTAGE trials

\begin{tabular}{|c|c|c|c|}
\hline & \multicolumn{2}{|l|}{ INPULSIS } & \multirow{2}{*}{$\begin{array}{l}\text { INSTAGE } \\
\text { Nintedanib }(n=136)\end{array}$} \\
\hline & Nintedanib $(n=638)$ & Placebo $(n=423)$ & \\
\hline Age, years, mean (SD) & $66.6(8.1)$ & $67.0(7.9)$ & $70.0(7.9)$ \\
\hline Male, n (\%) & $507(79.5)$ & $334(79.0)$ & $106(77.9)$ \\
\hline Body mass index, $\mathrm{kg} / \mathrm{m}^{2}$ & $28.1(4.6)$ & $27.6(4.6)$ & $26.5(4.7)$ \\
\hline \multicolumn{4}{|l|}{ Race, n (\%) } \\
\hline White & $360(56.4)$ & $248(58.6)$ & $95(69.9)$ \\
\hline Asian & $194(30.4)$ & $128(30.3)$ & $39(28.7)$ \\
\hline Other $^{a}$ & $84(13.2)$ & $47(11.1)$ & $2(1.5)$ \\
\hline Time since diagnosis of IPF, years, mean (SD) & $1.7(1.4)$ & $1.6(1.3)$ & $2.1(1.8)$ \\
\hline FVC, \% predicted, mean (SD) & $79.7(17.6)$ & $79.3(18.2)$ & $66.1(18.7)$ \\
\hline $\mathrm{FEV}_{1} / \mathrm{FVC}$ ratio, \%, mean (SD) & $81.7(5.8)$ & $81.7(6.0)$ & $83.8(7.6)$ \\
\hline DLco, \% predicted, mean $(S D)^{b}$ & $47.4(13.5)$ & $47.0(13.4)$ & $25.6(7.0)$ \\
\hline SGRQ total score, mean $(S D)^{c}$ & $39.5(19.2)$ & $39.6(18.5)$ & $54.0(17.9)$ \\
\hline
\end{tabular}

ancludes patients with missing data. In INPULSIS, it was not permitted to collect data on race in France. ${ }^{\mathrm{b}}$ Corrected for haemoglobin; INPULSIS: $n=422$ in placebo group; INSTAGE: $n=135$ in nintedanib group. 'INPULSIS: $n=624$ in nintedanib group and $n=419$ in placebo group; INSTAGE: $n=133$ in nintedanib group 


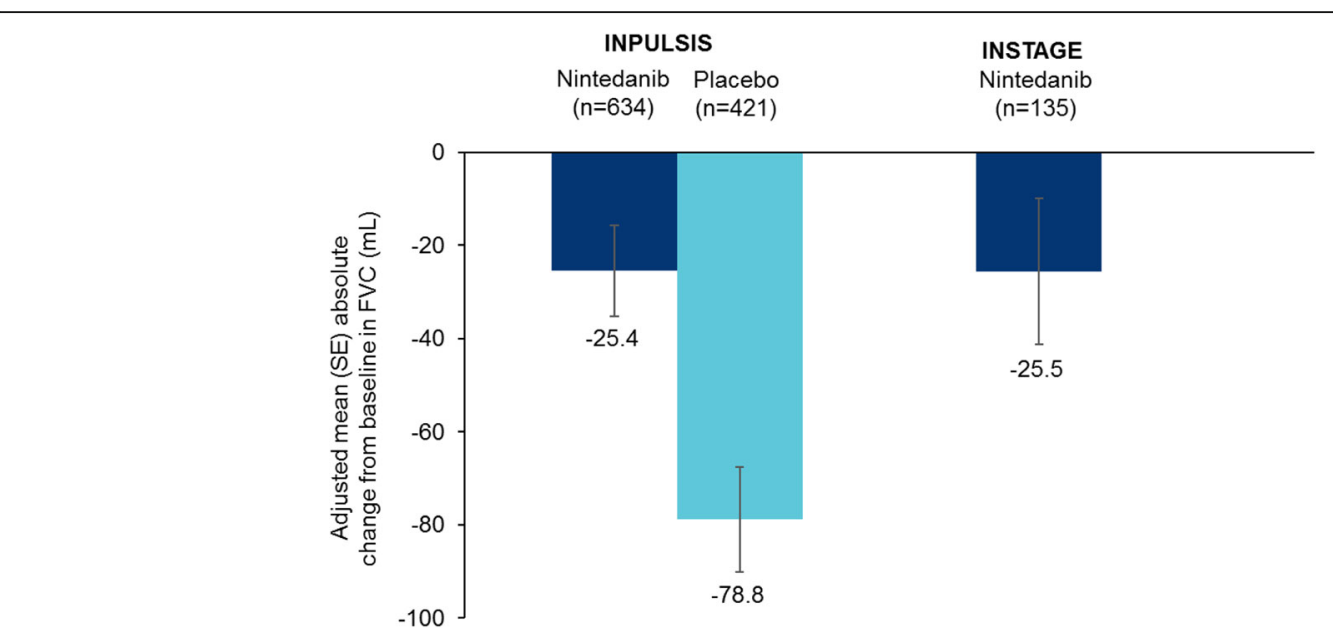

Fig. 1 Absolute changes from baseline in FVC $(\mathrm{mL})$ at week 12 in the INPULSIS and INSTAGE trials

INSTAGE, respectively, and in 8 (1.9\%) patients treated with placebo in INPULSIS.

\section{Safety and tolerability}

An overview of adverse events reported in the INPULSIS and INSTAGE trials is provided in Table 2. Adverse events leading to treatment discontinuation were reported in $90(14.1 \%)$ and 23 (16.9\%) patients treated with nintedanib alone in INPULSIS and INSTAGE, respectively, and $32(7.6 \%)$ patients who received placebo in INPULSIS. Diarrhoea was reported in 335 (52.5\%) and 66 (48.5\%) patients treated with nintedanib alone in INPULSIS and INSTAGE, respectively, and 68 (16.1\%) patients treated with placebo in INPULSIS, and led to premature treatment discontinuation in $24(3.8 \%)$ and $3(2.2 \%)$ patients treated with nintedanib in INPULSIS and INSTAGE, respectively, and in no patients who received placebo. Serious adverse events were reported in 107 (16.8\%) and 44
(32.4\%) patients treated with nintedanib alone in INPULSIS and INSTAGE, respectively, and 72 (17.0\%) patients treated with placebo in INPULSIS (Table 3).

\section{Discussion}

Patients with severe lung function impairment have been excluded from most clinical trials of treatments for IPF. As a result, far fewer data are available on the efficacy and safety of therapies in patients with advanced disease than milder disease. Here we have shown, based on data from the INPULSIS and INSTAGE trials, that nintedanib appears to have a similar effect on FVC decline over 24 weeks in patients with IPF irrespective of their severity of gas exchange impairment at baseline. Previous analyses of data from the INPULSIS trials have shown that nintedanib has a consistent effect in reducing FVC decline in subgroups of patients with baseline DLco $\leq 40 \%$ versus $>40 \%$ predicted [12] and $\mathrm{FVC} \leq 70 \%$ versus

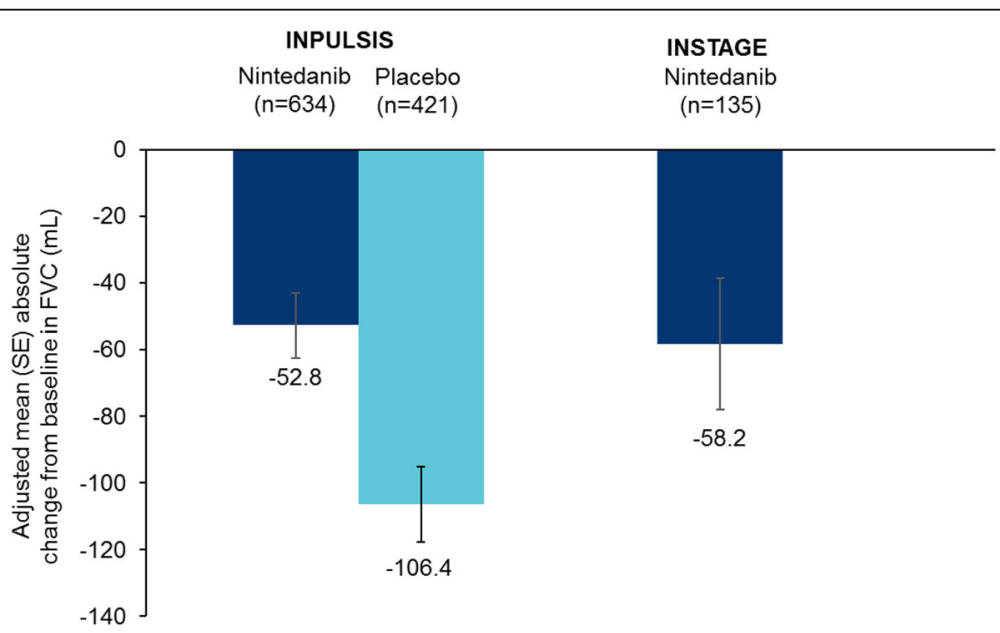

Fig. 2 Absolute changes from baseline in FVC $(\mathrm{mL})$ at week 24 in the INPULSIS and INSTAGE trials 


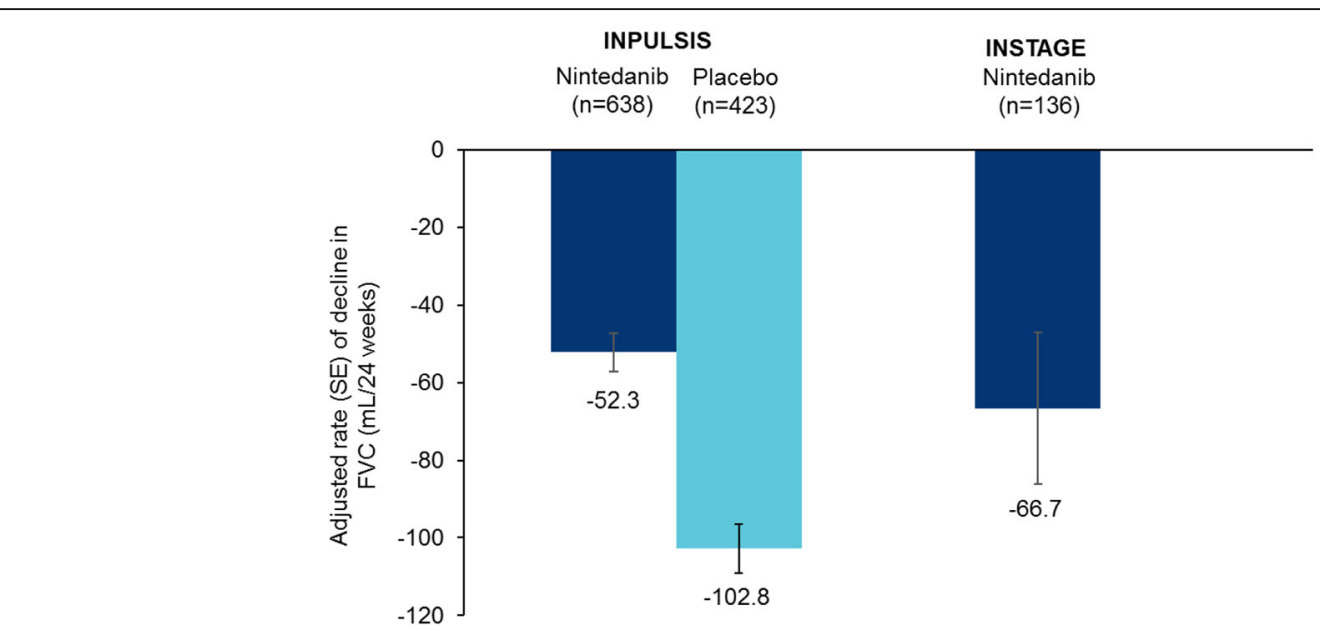

Fig. 3 Rate of decline in FVC (mL/24 weeks) in the INPULSIS and INSTAGE trials

$>70 \%$ predicted [13]. Data from an interim analysis of INPULSIS-ON, the open-label extension of the INPULSIS trials, suggested that, albeit with the limitations of an open-label design and small sample size, the efficacy and safety of nintedanib were similar in patients with FVC $\leq 50 \%$ predicted at entry into INPULSIS-ON as in patients with less severe disease [14]. A growing body of observational evidence collected in clinical practice suggests that nintedanib is efficacious in reducing disease progression in patients with severe lung function impairment [15-19]. Taken together, these findings support the use of nintedanib in patients with IPF who have advanced disease.

Physicians may be reluctant to treat patients with advanced IPF due to uncertainty about the efficacy and/or safety of antifibrotic therapies in these patients, or to

Table 2 Adverse events in the INPULSIS and INSTAGE trials

\begin{tabular}{|c|c|c|c|}
\hline & \multicolumn{2}{|l|}{ INPULSIS } & \multirow{2}{*}{$\begin{array}{l}\text { INSTAGE } \\
\text { Nintedanib }(n=136)\end{array}$} \\
\hline & Nintedanib $(n=638)$ & Placebo $(n=423)$ & \\
\hline Adverse events & $580(90.9)$ & $345(81.6)$ & $127(93.4)$ \\
\hline \multicolumn{4}{|l|}{ Most frequent adverse events ${ }^{a}$} \\
\hline Diarrhoea & $335(52.5)$ & $68(16.1)$ & $66(48.5)$ \\
\hline Nausea & $145(22.7)$ & $25(5.9)$ & $14(10.3)$ \\
\hline Decreased appetite & $53(8.3)$ & $16(3.8)$ & $23(16.9)$ \\
\hline Nasopharyngitis & $62(9.7)$ & $43(10.2)$ & $8(5.9)$ \\
\hline Cough & $61(9.6)$ & $35(8.3)$ & $13(9.6)$ \\
\hline Vomiting & $61(9.6)$ & $11(2.6)$ & $10(7.4)$ \\
\hline Dyspnoea & $30(4.7)$ & $25(5.9)$ & $13(9.6)$ \\
\hline Progression of $\mathrm{IPF}^{\mathrm{b}}$ & $33(5.2)$ & $34(8.0)$ & $12(8.8)$ \\
\hline Weight decreased & $41(6.4)$ & $8(1.9)$ & $12(8.8)$ \\
\hline Abdominal pain & $53(8.3)$ & $6(1.4)$ & $9(6.6)$ \\
\hline Adverse events leading to treatment discontinuation & $90(14.1)$ & $32(7.6)$ & $26(19.1)$ \\
\hline \multicolumn{4}{|c|}{ Most frequent adverse events leading to treatment discontinuation ${ }^{c}$} \\
\hline Diarrhoea & $24(3.8)$ & 0 & $3(2.2)$ \\
\hline Nausea & $12(1.9)$ & 0 & 0 \\
\hline Progression of IPF ${ }^{b}$ & $7(1.1)$ & $12(2.8)$ & 0 \\
\hline
\end{tabular}

Data are $\mathrm{n}(\%)$ of patients with $\geq 1$ such event. In INPULSIS, events with onset between the first dose of trial drug and day 195 (or between the first dose and 28 days after the last dose for patients who discontinued trial drug before week 24) were included. In INSTAGE, events with onset between the first dose and up to 28 days after the last dose of trial drug were included. ${ }^{a}$ Reported in $>8 \%$ of patients in any of the groups shown, based on MedDRA preferred terms.

${ }^{b}$ Corresponds to MedDRA term 'IPF', which included disease worsening and acute exacerbations. 'Reported in $>1.5 \%$ of patients in any of the groups shown, based on MedDRA preferred terms 
Table 3 Serious adverse events in the INSTAGE and INPULSIS trials

\begin{tabular}{|c|c|c|c|}
\hline & \multicolumn{2}{|l|}{ INPULSIS } & \multirow{2}{*}{$\begin{array}{l}\text { INSTAGE } \\
\text { Nintedanib }(n=136)\end{array}$} \\
\hline & Nintedanib $(n=638)$ & Placebo $(n=423)$ & \\
\hline Serious adverse events ${ }^{a}$ & $107(16.8)$ & $72(17.0)$ & $44(32.4)$ \\
\hline \multicolumn{4}{|l|}{ Most frequent serious adverse events ${ }^{b}$} \\
\hline Progression of $\mathrm{IPF}^{\mathrm{C}}$ & $23(3.6)$ & $21(5.0)$ & $9(6.6)$ \\
\hline Pneumonia & $14(2.2)$ & $10(2.4)$ & $8(5.9)$ \\
\hline Pulmonary hypertension & $4(0.6)$ & $7(1.7)$ & $4(2.9)$ \\
\hline Respiratory failure & 0 & 0 & $3(2.2)$ \\
\hline Right ventricular failure & 0 & 0 & $3(2.2)$ \\
\hline Pulmonary embolism & $3(0.5)$ & $2(0.5)$ & $2(1.5)$ \\
\hline Lower respiratory tract infection & $1(0.2)$ & $2(0.5)$ & $2(1.5)$ \\
\hline Respiratory tract infection & 0 & $2(0.5)$ & $2(1.5)$ \\
\hline Dyspnoea & $1(0.2)$ & $2(0.5)$ & $2(1.5)$ \\
\hline Acute respiratory failure & $2(0.3)$ & $1(0.2)$ & $2(1.5)$ \\
\hline
\end{tabular}

Data are $\mathrm{n}(\%)$ of patients with $\geq 1$ such event. In INPULSIS, events with onset between the first dose of trial drug and day 195 (or between the first dose and 28 days after the last dose for patients who discontinued trial drug before week 24) were included. In INSTAGE, events with onset between the first dose and up to 28 days after the last dose of trial drug were included. ${ }^{a}$ Events that resulted in death, were life-threatening, resulted in hospitalisation or prolonged hospitalisation, resulted in persistent or clinically significant disability or incapacity, were a congenital anomaly or birth defect, or were deemed serious for any other reason. ${ }^{\mathrm{b}}$ Reported in $\geq 1.5 \%$ of patients in any of the groups shown, based on MedDRA preferred terms. 'Corresponds to MedDRA term 'IPF', which included disease worsening and acute exacerbations

concerns over the tolerability of antifibrotic therapies in patients who are old or have comorbidities [20]. However, many of the patients with IPF who require care in clinical practice have advanced impairment in lung function. Data from 662 patients in the IPF-PRO Registry, a US registry of patients with IPF that was diagnosed or confirmed at the enrolling centre in the past 6 months, showed that $25 \%$ of patients had DLco $<31.3 \%$ predicted and $25 \%$ had FVC $<60.1 \%$ predicted [21]. Similar degrees of impairment in FVC and DLco have been observed in other contemporary registries of patients with IPF [22].

Nintedanib had a similar adverse event profile in patients with mild or moderate impairment in gas exchange in the INPULSIS trials and in patients with more severe disease in the INSTAGE trial, albeit with a greater frequency of serious adverse events in patients with more severe disease, as might be expected in a sicker population. Previous analyses of safety data from clinical trials of nintedanib have shown a consistent safety and tolerability profile across trials and patient subgroups $[13,14,23]$. Real-world data from clinical practice suggest that the safety and tolerability profile of nintedanib is similar in patients with IPF who have severe disease as in patients with milder disease, but that patients with more severe disease have a higher rate of treatment discontinuation $[16,18,24]$. This highlights the importance of patient education and proactive management of sideeffects in patients prescribed nintedanib for the treatment of IPF $[25,26]$.

In our analyses, HRQL at baseline, assessed using the SGRQ total score, was worse in patients in the
INSTAGE trial than in the INPULSIS trials. Previous studies have also shown that patients with IPF who have more advanced disease based on \% predicted values for FVC and/or DLco have worse symptoms, worse exercise capacity, and worse HRQL [27-29]. In both the INPULSIS and INSTAGE trials, changes in SGRQ total score over 24 weeks were small, consistent with previous studies showing that small changes in FVC are not associated with meaningful changes in the patient-reported outcomes commonly used in patients with IPF [30, 31].

As expected, the risk of idiopathic acute exacerbations was higher in patients with more advanced disease in the INSTAGE trial than in patients in the INPULSIS trials. A wealth of data has demonstrated that low FVC and/or low DLco are risk factors for acute exacerbations in patients with IPF [11, 32, 33], possibly because patients with more advanced disease are more vulnerable to insults such as infection that may lead to an acute exacerbation [11]. Similarly, the risk of mortality was higher in patients with more severe impairment in DLco in the INSTAGE trial than in patients in the INPULSIS trials, consistent with previous studies identifying low DLco as a risk factor for mortality in patients with IPF [4, 33, 34].

Our analyses have limitations, including differences between the INPULSIS and INSTAGE trial populations beyond impairment in lung function; the lack of a placebo group in the INSTAGE trial; the short duration of the study; the use of different equations for calculation of per cent predicted values for DLco; and the post-hoc nature of the analyses of data from the INPULSIS trials. Nonetheless, our data add to the body of evidence on 
the efficacy and safety of nintedanib in patients with IPF and advanced disease.

\section{Conclusion}

Based on data from the INPULSIS and INSTAGE trials, nintedanib appears to have a similar effect on FVC decline over 24 weeks, and a similar safety and tolerability profile, in patients with IPF irrespective of their severity of gas exchange impairment at baseline. These data support the use of nintedanib in patients with IPF who have advanced disease.

\section{Abbreviations}

bid: Twice daily; DLco: Diffusing capacity of the lungs for carbon monoxide; $\mathrm{FEV}_{1}$ : Forced expiratory volume in $1 \mathrm{~s}$; FVC: Forced vital capacity; HRQL: Health-related quality of life; IPF: Idiopathic pulmonary fibrosis; MedDRA: Medical Dictionary for Regulatory Activities; SGRQ: St. George's Respiratory Questionnaire

\section{Acknowledgements}

Writing assistance, supported financially by Boehringer Ingelheim, was provided by Julie Fleming and Wendy Morris of FleishmanHillard Fishburn, London, UK, during the development of this manuscript. The authors were fully responsible for all content and editorial decisions, were involved at all stages of development and provided their approval on the final version.

\section{Authors' contributions}

$L R, M K, B S, S S, M Q$ and GR contributed to the design of the study. LR, MK, SJ, WAW and GR contributed to the acquisition of the data. All authors contributed to the interpretation of the data. All authors critically revised the manuscript and approved the final version for submission.

\section{Funding}

The INPULSIS and INSTAGE trials were funded by Boehringer Ingelheim. Employees of Boehringer Ingelheim were involved in the design of these trials, in data collection and analysis, in the interpretation of the data and in writing the manuscript.

\section{Availability of data and materials}

All the data generated or analyzed for the purposes of this study are included in the published article.

\section{Ethics approval and consent to participate}

The INPULSIS and INSTAGE trials were carried out in compliance with the principles of the Declaration of Helsinki and the Harmonized Tripartite Guideline for Good Clinical Practice from the International Conference on Harmonization, and were approved by local authorities. All patients provided written informed consent before study entry.

\section{Consent for publication}

Not applicable.

\section{Competing interests}

$L R$ reports grants and personal fees from Boehringer Ingelheim and Roche; and personal fees from Asahi Kasei, Biogen, Bristol-Myers Squibb, Celgene, CSL Behring, FibroGen, ImmuneWorks, Nitto, Pliant Therapeutics, Promedior, Respivant, and Toray. MK reports grants and personal fees from Boehringer Ingelheim, Gilead, GlaxoSmithKline, Prometic, and Roche; grants from Actelion, Alkermes, Pharmaxis, and RespiVert; and personal fees from Genoa, Indalo, and Third Pole. SJ has received fees, funding, or reimbursement for participation at meetings from Actelion, AIRB, AstraZeneca, Boehringer Ingelheim, Bristol-Myers Squibb, Chiesi, Gilead, GlaxoSmithKline, LVL, Mundipharma, Novartis, Pfizer, Roche, and Savara-Serendex. WAW reports grants to his institution from Boehringer Ingelheim and Roche and personal fees from Boehringer Ingelheim. BS, SS and MQ are employees of Boehringer Ingelheim, which funded the INPULSIS and INSTAGE trials; BS, SS and MQ were involved in the design of these trials, in the interpretation of the data and in writing the manuscript. BS was involved in analysing the data. GR has acted as a consultant for Bellerophon, Biogen, Boehringer Ingelheim, Bristol-Myers Squibb, FibroGen, Gilead, Nitto, Patara, Promedior, Sanofi, and Veracyte; has received a grant from the US National Institute of Health; and is a principal investigator and steering committee member for IPFnet studies.

\section{Author details}

${ }^{1}$ Fondazione Policlinico A. Gemelli IRCCS, Università Cattolica del Sacro Cuore, Rome, Italy. ${ }^{2}$ McMaster University and St. Joseph's Healthcare, Hamilton, Ontario, Canada. ${ }^{3}$ Hôpital Pontchaillou - CHU de Rennes, IRSET UMR 1085, Université de Rennes 1, Rennes, France. ${ }^{4}$ Unit for Interstitial Lung Diseases, Department of Respiratory Medicine, University Hospitals Leuven, Leuven, Belgium. ${ }^{5}$ Boehringer Ingelheim International $\mathrm{GmbH}$, Ingelheim, Germany. ${ }^{6}$ University of Washington, Seattle, USA.

Received: 24 July 2019 Accepted: 12 December 2019

Published online: 08 January 2020

\section{References}

1. Raghu G, Remy-Jardin M, Myers JL, Richeldi L, Ryerson CJ, Lederer DJ, et al. Diagnosis of idiopathic pulmonary fibrosis. An official ATS/ERS/JRS/ALAT clinical practice guideline. Am J Respir Crit Care Med. 2018;198:e44-68.

2. Kreuter M, Swigris J, Pittrow D, Geier S, Klotsche J, Prasse A, et al. The clinical course of idiopathic pulmonary fibrosis and its association to quality of life over time: longitudinal data from the INSIGHTS-IPF registry. Respir Res. 2019;20:59.

3. Reichmann WM, Yu YF, Macaulay D, Wu EQ, Nathan SD. Change in forced vital capacity and associated subsequent outcomes in patients with newly diagnosed idiopathic pulmonary fibrosis. BMC Pulm Med. 2015;15:167.

4. Doubková M, Švancara J, Svoboda M, Šterclová M, Bartoš V, Plačková M, et al. EMPIRE registry, Czech part: impact of demographics, pulmonary function and HRCT on survival and clinical course in idiopathic pulmonary fibrosis. Clin Respir J. 2018;12:1526-35.

5. Caminati A, Cassandro R, Torre O, Harari S. Severe idiopathic pulmonary fibrosis: what can be done? Eur Respir Rev. 2017;26:170047.

6. Richeldi L, du Bois RM, Raghu G, Azuma A, Brown KK, Costabel U, et al. Efficacy and safety of nintedanib in idiopathic pulmonary fibrosis. $\mathrm{N}$ Engl J Med. 2014;370:2071-82

7. Kolb M, Raghu G, Wells AU, Behr J, Richeldi L, Schinzel B, et al. Nintedanib plus sildenafil in patients with idiopathic pulmonary fibrosis. N Engl J Med. 2018;379:1722-31.

8. Quanjer PH, Tammeling GJ, Cotes JE, OF P, Peslin R, Yernault JC. Lung volumes and forced ventilatory flows. Report working party standardization of lung function tests, European Community for Steel and Coal Official statement of the European Respiratory Society. Eur Respir J Suppl. 1993;16:5-40.

9. Crapo RO, Morris AH, Gardner RM. Reference values for pulmonary tissue volume, membrane diffusing capacity and pulmonary capillary blood volume. Bull Eur Physiopathol Respir. 1982;18:893-9.

10. Jones PW, Quirk FH, Baveystock CM. The St George's Respiratory Questionnaire. Respir Med. 1991;85(Suppl B):25-31 discussion 33-7.

11. Collard HR, Ryerson CJ, Corte TJ, Jenkins G, Kondoh Y, Lederer DJ, et al. Acute exacerbation of idiopathic pulmonary fibrosis. An international working group report. Am J Respir Crit Care Med. 2016;194:265-75.

12. Brown KK, Flaherty KR, Cottin V, Raghu G, Inoue Y, Azuma A, et al. Lung function outcomes in the INPULSIS trials of nintedanib in idiopathic pulmonary fibrosis. Respir Med. 2019;146:42-8.

13. Costabel U, Inoue Y, Richeldi L, Collard HR, Tschoepe I, Stowasser S, Azuma A. Efficacy of nintedanib in idiopathic pulmonary fibrosis across prespecified subgroups in INPULSIS. Am J Respir Crit Care Med. 2016;193:178-85.

14. Wuyts WA, Kolb M, Stowasser S, Stansen W, Huggins JT, Raghu G. First data on efficacy and safety of nintedanib in patients with idiopathic pulmonary fibrosis and forced vital capacity of $\leq 50 \%$ of predicted value. Lung. 2016; 194:739-43.

15. Hughes G, Toellner H, Morris H, Leonard C, Chaudhuri N. Real world experiences: pirfenidone and nintedanib are effective and well tolerated treatments for idiopathic pulmonary fibrosis. J Clin Med. 2016;5:E78.

16. Abe M, Tsushima K, Sakayori M, Suzuki K, Ikari J, Terada J, Tatsumi K. Utility of nintedanib for severe idiopathic pulmonary fibrosis: a single-center retrospective study. Drug Des Devel Ther. 2018;12:3369-75.

17. Harari S, Caminati A, Poletti V, Confalonieri M, Gasparini S, Lacedonia D, et al. A real-life multicenter national study on nintedanib in severe idiopathic pulmonary fibrosis. Respiration. 2018;95:433-40. 
18. Yoon HY, Park S, Kim DS, Song JW. Efficacy and safety of nintedanib in advanced idiopathic pulmonary fibrosis. Respir Res. 2018;19:203.

19. Barczi E, Starobinski L, Kolonics-Farkas A, Eszes N, Bohacs A, Vasakova M, et al. Long-term effects and adverse events of nintedanib therapy in idiopathic pulmonary fibrosis patients with functionally advanced disease. Adv Ther. 2019:36:1221-32.

20. Maher TM, Swigris JJ, Kreuter M, Wijsenbeek M, Cassidy N, Ireland L, et al. Identifying barriers to idiopathic pulmonary fibrosis treatment: a survey of patient and physician views. Respiration. 2019;96:514-24.

21. Culver D, Yow E, Neely ML, Belperio JA, Bender S, de Andrade JA, et al. Characteristics of patients with idiopathic pulmonary fibrosis (IPF) in the US: data from the IPF-PRO registry: Data presented at Chest annual congress. Boehringer Ingelheim; 2018. Available at: http://uspubs-posters.com/chest2 018/culver

22. Culver DA, Behr J, Belperio JA, Corte TJ, de Andrade JA, Flaherty KR, et al. Patient registries in idiopathic pulmonary fibrosis (IPF). Am J Respir Crit Care Med. 2019;200:160-7.

23. Lancaster L, Crestani B, Hernandez P, Inoue Y, Wachtlin D, Loaiza L, et al. Safety and survival data in patients with idiopathic pulmonary fibrosis treated with nintedanib: pooled data from six clinical trials. BMJ Open Respir Res. 2019;6:e000397.

24. Fletcher SV, Jones MG, Renzoni EA, Parfrey H, Hoyles RK, Spinks K, et al. Safety and tolerability of nintedanib for the treatment of idiopathic pulmonary fibrosis in routine UK clinical practice. ERJ Open Res. 2018;4: 00049-2018.

25. Corte T, Bonella F, Crestani B, Demedts MG, Richeldi L, Coeck C, et al. Safety, tolerability and appropriate use of nintedanib in idiopathic pulmonary fibrosis. Respir Res. 2015;16:116.

26. Bendstrup E, Wuyts W, Alfaro T, Chaudhuri N, Cornelissen R, Kreuter M, et al. Nintedanib in idiopathic pulmonary fibrosis: practical management recommendations for potential adverse events. Respiration. 2019;97:173-84.

27. Bahmer T, Kirsten AM, Waschki B, Rabe KF, Magnussen H, Kirsten D, et al. Clinical correlates of reduced physical activity in idiopathic pulmonary fibrosis. Respiration. 2016;91:497-502.

28. Kreuter M, Swigris J, Pittrow D, Geier S, Klotsche J, Prasse A, et al. Health related quality of life in patients with idiopathic pulmonary fibrosis in clinical practice: INSIGHTS-IPF registry. Respir Res. 2017;18:139.

29. Jo HE, Glaspole I, Moodley Y, Chapman S, Ellis S, Goh N, et al. Disease progression in idiopathic pulmonary fibrosis with mild physiological impairment: analysis from the Australian IPF registry. BMC Pulm Med. 2018;18:19.

30. Swigris JJ, Kuschner WG, Jacobs SS, Wilson SR, Gould MK. Health-related quality of life in patients with idiopathic pulmonary fibrosis: a systematic review. Thorax. 2005;60:588-94.

31. Swigris JJ, Wilson H, Esser D, Conoscenti CS, Stansen W, Kline Leidy N, Brown KK. Psychometric properties of the St George's respiratory questionnaire in patients with idiopathic pulmonary fibrosis: insights from the INPULSIS trials. BMJ Open Respir Res. 2018;5:e000278.

32. Collard HR, Richeldi L, Kim DS, Taniguchi H, Tschoepe I, Luisetti M, et al. Acute exacerbations in the INPULSIS trials of nintedanib in idiopathic pulmonary fibrosis. Eur Respir J. 2017:49(5):1601339.

33. Paterniti MO, Bi Y, Rekić D, Wang Y, Karimi-Shah BA, Chowdhury BA. Acute exacerbation and decline in forced vital capacity are associated with increased mortality in idiopathic pulmonary fibrosis. Ann Am Thorac Soc. 2017;14:1395-402.

34. Snyder L, Neely ML, Hellkamp AS, O'Brien E, de Andrade J, Conoscenti CS, et al. Predictors of death or lung transplant after a diagnosis of idiopathic pulmonary fibrosis: insights from the IPF-PRO registry. Respir Res. 2019;20:105.

\section{Publisher's Note}

Springer Nature remains neutral with regard to jurisdictional claims in published maps and institutional affiliations.

Ready to submit your research? Choose BMC and benefit from:

- fast, convenient online submission

- thorough peer review by experienced researchers in your field

- rapid publication on acceptance

- support for research data, including large and complex data types

- gold Open Access which fosters wider collaboration and increased citations

- maximum visibility for your research: over $100 \mathrm{M}$ website views per year

At BMC, research is always in progress.

Learn more biomedcentral.com/submissions 